\title{
Parametric Study of the NRCC Fire Risk-Cost Assessment Model for Apartment and Office Buildings
}

\author{
GEORGE V. HADJISOPHOCLEOUS and DAVID YUNG \\ National Fire Laboratory \\ National Research Council Canada \\ Ottawa, Ontario, Canada, K1A OR6
}

\begin{abstract}
This paper describes a model developed for the evaluation of risks and costs from fires in office and apartment buildings. It uses both deterministic and stochastic techniques to evaluate the consequence of all possible fire scenarios that may occur in a building. The probability of each scenario occurring and the consequence of that scenario are combined, resulting in two performance parameters: the expected risk to life (ERL) and the fire cost expectation. In this paper, a brief description of the system model and the methodology used is given, as well as the results of a study showing the sensitivity of the expected risk to life to various input parameters for a three storey apartment building. The results show that fire resistance, when there are no sprinklers present, has a great impact on lowering the expected risk-to-life. When there are sprinklers present, however, its impact is insignificant. The results show that the installation of sprinkler systems is important; the ERL values are much lower for designs with sprinklers than those without sprinklers. In general, for this building, the presence of active fire protection systems is important, however, the variation of the reliability of these systems, within a reasonable range, is not critical.
\end{abstract}

KEYWORDS: Risk analysis, fire model, fire brigade model, smoke movement, fire spread.

\section{INTRODUCTION}

The assessment of the level of fire safety in a building is not an easy task and, until recently, the only methods available for such assessments were point rating forms that required the subjective judgment of the evaluator $[1,2]$. Due to the subjectivity of these 
methods, it is possible to get different levels of safety from different evaluators. These methods are really not designed to evaluate the actual fire safety level in a building; rather, they are designed to assess how well the building conforms to existing codes and standards. Conformance to these regulations, however, does not necessarily imply that a cost-effective design is achieved; such a design is one that will provide an acceptable level of safety to the occupants at a minimal cost. To be able to quantify the level of safety in a building, it is necessary to consider how the building, as a system, reacts to fires. This system includes the structure, the contents, the occupants, the fire protection systems and the functions and operations taking place in the building. Only when the building is considered as a system, is it possible to evaluate the impact of the various protection systems on the risk to the occupants and the associated costs.

The development of tools that can evaluate the level of safety of a "building system" is a necessary step towards the introduction of performance-based building codes to replace the existing prescription-based codes. The move towards performance-based codes is happening in many countries, including Australia, New Zealand, and the U.K.. As a result of this trend towards performance-based codes, many researchers have focused their interest in the development of computer models that can be used to assess the fire safety performance of buildings. Many of these models are described in a recent survey of international computer models by Friedman [3]. Most of the models described in this survey, however, focus on a single aspect of the fire problem and cannot really be used for comprehensive risk evaluation. Only one model was developed for this purpose: the Risk-Cost Assessment Model being developed at the National Research Council of Canada (NRCC) in collaboration with the Victoria University of Technology in Australia [4-7].

The NRCC model evaluates the level of safety in a building by considering the building as a system. The response of the building system to all probable fire scenarios that may occur in the building is evaluated in a systematic way to arrive at the values of two performance parameters: the Expected Risk-to-Life (ERL) and the Fire-Cost Expectation (FCE). The expected risk-to-life is defined as the expected number of deaths in a building from all probable fires during the design life of the building divided by the building population and by the building life. The fire-cost expectation is defined as the present worth of the total fire-related costs, which include the capital costs for the installation of fire protection systems, the maintenance costs for the active fire protection systems and the expected losses from all fires in the building during the design life of the building. With these two parameters, the need to assign a monetary value to a human life is avoided and an explicit estimate of the risk to life afforded to the building occupants and the associated costs to provide such protection is obtained.

The present NRCC model is suitable for comparative risk and cost assessments and not for absolute assessments for the following reasons. First, due to the complexity of the problem and the lack of sufficient understanding of fire phenomena and human behaviour, certain conservative assumptions were made in the mathematical modelling. Secondly, a comparative assessment eliminates the need to define acceptable levels of risk which is a very difficult task. In the NRCC approach, the two performance parameters, obtained for a building when all building code requirements are satisfied, are used as reference values against which the parameters obtained for alternative designs are compared. If an alternative design results in an expected risk-to-life value lower than that obtained for the codecomplying design, then the alternative design is considered acceptable. Comparing the fire- 
cost expectation of all designs that satisfy the first criterion, enables the selection of a costeffective design which offers an acceptable level of risk at the lowest cost.

\section{SYSTEM MODEL DESCRIPTION}

The system model consists of a number of subsidiary deterministic and stochastic submodels that calculate fire growth, fire spread, smoke movement in the building, fire detection, warning and occupant response, fire brigade action and egress of occupants. Details of these submodels have been described previously [4-7]. In this paper, only recent developments, such as the use of design fires, the handling of the sprinkler system and the modelling of the effects of the fire brigade actions are described.

\section{Design Fires and Fire Scenarios}

To carry out a proper fire risk analysis, it is important to identify all possible fire scenarios that may occur in a building, evaluate these scenarios to determine their impact on life and cost and then combine the results of all scenarios together with the probabilities of these scenarios to obtain the overall expected risk and losses. In reality, fires can occur anywhere in the building and can be of any intensity. It is not possible for an analysis, however, to consider the infinite number of possible fires. To overcome this problem, all fires that may occur in a building are grouped into six design fires as follows:

1. Smouldering fires with fire compartment entrance door open;

2. Smouldering fires with fire compartment entrance door closed;

3. Flaming non-flashover fires with fire compartment entrance door open;

4. Flaming non-flashover fires with fire compartment entrance door closed;

5. Flashover fires with fire compartment entrance door open; and

6. Flashover fires with fire compartment entrance door closed.

The probability of occurrence of each design fire, given that a fire has occurred, is based on statistics $[8,9]$. As the location of the fire in a building affects the smoke movement and fire spread, the NRCC model considers the possibility of fire starting on every floor. Similarly, the ambient conditions also affect the fire development and smoke movement in a building due to stack effect. In the NRCC model, the ambient conditions are grouped into three seasons: summer, winter and spring/fall. Finally, the effect of each design fire on the occupants depends on whether the occupants are asleep or awake. The model considers two conditions: occupants asleep and occupants awake separately and evaluates the expected number of deaths for both conditions.

Figure 1 shows the different fire scenarios that are considered on the first floor of a building for flashover fires with the compartment entrance door open. These scenarios will be evaluated for each floor in the building. In a three-storey building, the total number of fire scenarios that will be evaluated are: 6 design fires $x 3$ seasons $x 2$ occupant conditions $x$ 3 storeys. This is equal to 108 fire scenarios. With this large number of fire scenarios, it is essential that the models be simplified enough so they can run within a reasonable time without compromising on the overall accuracy of the results. 


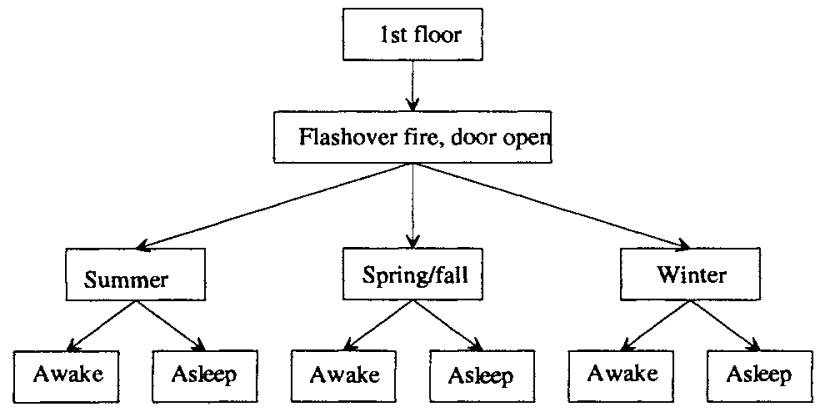

FIGURE 1. Fire scenarios for flashover fires with door open.

\section{Fire Development}

The development of any of the design fires in the compartment of fire origin is computed by the model, using a one zone approach, in terms of the heat release rate, temperature and concentration of toxic gases, as well as the flow of gases out of the compartment. The fire growth characteristics depend on the fire load in the compartment, its distribution, the size of the compartment and the ventilation openings. This calculation continues until all the combustibles in that compartment are consumed by the fire. Details of the fire growth model are described in [10].

From the fire growth characteristics, a number of characteristic states are defined during the fire development process. These states, which are used to evaluate fire detection, occupant warning, response and egress, are as follows:

a) State I-time of fire cue. State $\mathrm{I}$ is defined as the time when the fire can be detected by one of the human senses (visual, olfactory, auditory). This state is assumed to occur at the time when the upper layer descends to a level equal to 0.95 times the floor to ceiling height of the compartment of fire origin [11].

b) State II - time of smoke detector activation. State II is defined as the time when a smoke detector in the compartment of fire origin is activated. This time is assumed to be the time when the temperature in the compartment rises by $20^{\circ} \mathrm{C}$.

c) State III-time of sprinkler activation. State III is defined as the time when a sprinkler in the compartment of fire origin activates, which is assumed to occur at the time when the temperature in the compartment reaches $100^{\circ} \mathrm{C}$. This event is used as State III of the fire development and is applicable only to the flashover and the flaming non-flashover fires. In the case of smouldering fires, State III is defined as the time of fire brigade action computed by the Fire Brigade Action Model.

d) State IV - time of flashover. State IV is defined as the time when flashover is reached in the compartment of fire origin. It is assumed that flashover occurs when the temperature in the compartment of fire origin reaches $600^{\circ} \mathrm{C}$.

e) State V-Time of fire burnout State V is defined as the time when the fire is extinguished either because all the fire load in the compartment of fire origin is consumed or because it has not spread to other combustibles. 


\section{Modelling of the Effect of Sprinklers}

The risk-cost assessment model considers the effect of the sprinkler system indirectly. Instead of modelling the interaction of the waterspray from the sprinkler system with the fire and smoke, which is a complex task, the model considers the effect of the sprinklers using the following approach:

1. The installation and effective operation of a sprinkler system during a fire will extinguish the fire, resulting in minimal damage to the building and no loss of life.

2. For the small probability that the sprinkler system fails to extinguish a fire, the fire is assumed to burn as if there is no sprinkler system installed.

3. Smouldering fires will not activate sprinklers as they do not generate enough heat.

The activation and effective operation of the sprinkler system is defined by two factors; reliability and effectiveness. The reliability factor, $\operatorname{Pr}$, is the ratio of the number of fires during which a sprinkler system is expected to operate to the total number of fires. The effectiveness factor, $\mathrm{Pe}$, is the ratio of the number of fires that are expected to be extinguished by sprinklers, to the total number of fires in the building during which the sprinkler system has activated. As it is expected that the sprinkler system may not be activated by some small non-flashover fires, it is assumed that the reliability of the sprinkler system for non-flashover fires is $25 \%$ of that for flashover fires.

Based on these assumptions, the effect of the sprinkler system is incorporated in the model by modifying the probabilities of the design fires as follows:

$$
\begin{gathered}
\mathrm{PDFS}_{\mathrm{FL}}=\mathrm{PDF}_{\mathrm{FL}} *(1-\mathrm{Pr} * \mathrm{Pe}) \\
\mathrm{PDFS}_{\mathrm{NF}}=\mathrm{PDF}_{\mathrm{NF}} *\left(1-0.25^{*} \mathrm{Pr} * \mathrm{Pe}\right) \\
\mathrm{PDFS}_{\mathrm{SM}}=\mathrm{PDF}_{\mathrm{SM}} \\
\mathrm{PDFS}_{\mathrm{NL}}=\mathrm{PDF}_{\mathrm{NL}}+\mathrm{PDF}_{\mathrm{NF}} * 0.25 * \mathrm{Pr} * \mathrm{Pe}+\mathrm{PDF}_{\mathrm{FL}} * \mathrm{Pr} * \mathrm{Pe}
\end{gathered}
$$

where: $\quad$ PDFFL probability of flashover fires;

PDFNF probability of flaming non-flashover fires;

PDFSM probability of smouldering fires;

PDFNL probability of flaming non-lethal fires;

PDFS $_{F L} \quad$ probability of flashover fires with sprinklers installed;

PDFS $_{N F}$ probability of flaming non-flashover fires with sprinklers installed;

PDFS $_{S M}$ probability of smouldering fires with sprinklers installed; and

PDFS $_{\mathrm{NL}}$ probability of flaming non-lethal fires with sprinklers installed.

With the modified probabilities of the design fires, sprinkler systems are considered in a realistic way without having to actually model the interaction of fires and water. 


\section{Modelling of Fire Brigade Actions}

The risk to the occupants in buildings is affected by the actions of the fire department. A building which is located near a fire department that employs full time firefighters is expected to have better service during a fire than a building located remotely from the fire department. For this reason, the risk-cost model considers the effect of the fire department actions. It does so by using the probability of fire brigade action P[FBA] and the expected time of action tFBA. In general, $\mathrm{P}[\mathrm{FBA}]$ depends on the probabilities of detection at the three states of fire growth, as defined earlier, as well as whether or not there is a direct connection between the fire building and the fire brigade. The probability of notifying the fire brigade at State 1, which is the state of fire cue, depends on the probability that the fire will be detected by an occupant in the compartment of fire origin and that this occupant decides to call the fire department. This is modeled as:

$$
\mathrm{P}[\text { mann-a }]=\mathrm{P}[\operatorname{det} 1] * \mathrm{P}[\text { call }]
$$

where: P[mann-a] Probability of calling the fire department at State 1 by the occupant who detects the fire at this state;

P[det1] Probability of detection at State 1; and

$P$ [call] Conditional probability that occupants will call the fire department given that they have responded to the fire cue at State 1.

At this state, the fire brigade may also be notified by other occupants who have received the warning signals from the person who detects the fire and they decide to call the fire department. The probability of calling the fire department by these occupants is:

$$
\mathrm{P}[\text { mann-b }]=\mathrm{P}[\mathrm{DWR} 1] * \mathrm{P}[\mathrm{call}]
$$

where: P[mann-b] Probability of calling the fire department at State 1 by occupants who have been warned about the fire by other occupants; and

P[DWR1] Probability of detection, warning and occupant response at State 1.

The overall probability of notifying the fire department at State 1 is therefore:

$$
\mathrm{P}[\text { call1 }]=\mathrm{P}[\text { mann-a }]+\mathrm{P}[\text { mann-b }]-\mathrm{P}[\text { mann-a }] * \mathrm{P}[\text { mann-b }]
$$

where: $P$ [call1] Probability of calling the fire department at State 1;

The probability of calling the fire department at State 2, which is defined as the state of fire growth when smoke detectors activate, depends on two factors: First, it depends on whether or not the occupants will respond to a smoke detector warning given that the smoke detectors have detected the fire; and, secondly, it depends on whether or not the detectors are directly connected to the fire department. The probability that the fire department will be notified by the building occupants is:

$$
\mathrm{P}[\mathrm{mann}]=\mathrm{P}[\mathrm{DWR} 2] * \mathrm{P}[\mathrm{call}]
$$

where: $\mathrm{P}[\mathrm{mann}] \quad$ Probability that the fire department will be notified by the building occupants at State 2; 
P[DWR2] Probability of detection, warning and response at State 2.

The probability of directly notifying the fire department upon detection of the fire is:

$$
\mathrm{P}[\text { auto }]=\mathrm{P}[\operatorname{det} 2] * \mathrm{~F}[\text { conn }]
$$

where: $P$ [auto] Probability that the fire department will be notified automatically through the direct connection;

P[det2] Probability of detection at State 2;

$\mathrm{F}$ [conn] Flag having a value of 1 if there is a direct connection between the building and the fire department and a value of 0 if not.

The overall probability of notifying the fire department at State 2 is therefore:

$$
\mathrm{P}[\text { call2a }]=\mathrm{P}[\operatorname{mann}]+\mathrm{P}[\text { auto }]-\mathrm{P}[\mathrm{mann}] * \mathrm{P}[\text { auto }]
$$

The probability that the fire department will be notified at State 2 of fire development and not at State 1 is;

$$
\mathrm{P}[\text { call2 }]=(1-\mathrm{p}[\text { call1 }]) * \mathrm{P}[\text { call2a }]
$$

Following a similar approach, the independent probability of notifying the fire department at State 3 is modeled.

The overall probability of fire department notification during the development of a fire in the building is:

$$
\mathrm{P}[\mathrm{FBA}]=\mathrm{P}[\text { call } 1]+\mathrm{P}[\text { call } 2]+\mathrm{P}[\text { call } 3]
$$

where $\mathrm{P}[\mathrm{FBA}]$ is the probability of fire brigade action.

The time the fire brigade action at the building will commence depends on the time that the fire department is notified, the time needed for the fire brigade to respond to the notification, the time needed to travel to the fire location and the time required to set up their equipment and be ready for action. The only time that needs to be computed is the time of notification. The other times can be obtained from statistical data. The time for notification is modeled as follows:

$$
\mathrm{t}_{\mathrm{FBN}}=\left(\mathrm{P}[\text { call1 }]^{*} \mathrm{t}_{\operatorname{det} 1}+\mathrm{P}[\text { call2 }]^{*} \mathrm{t}_{\operatorname{det} 2}+\mathrm{P}[\text { call3 }]^{*} \mathrm{t}_{\operatorname{det} 3}\right) / \mathrm{P}[\mathrm{FBA}]
$$

The time of fire brigade action is then:

$$
t_{\mathrm{FBA}}=\mathrm{t}_{\mathrm{FBN}}+\mathrm{t}_{\mathrm{FBR}}+\mathrm{t}_{\mathrm{FBT}}+\mathrm{t}_{\mathrm{FBS}}
$$

where: $t_{\mathrm{FBA}} \quad$ time of fire brigade action;

$t_{\mathrm{FBN}} \quad$ time of fire brigade notification of a fire;

$t_{\mathrm{FBR}} \quad$ time of fire brigade response to a fire notification (2 min, [9]);

$\mathrm{t}_{\mathrm{FBT}} \quad$ time of fire brigade travel to the location of the fire (5 min [9]); and 


\section{Smoke Movement and Smoke Hazard}

The smoke movement model uses the results of the fire growth model to determine the conditions in the building in terms of smoke movement and the concentration of toxic gases at any location and the time when the stairs become untenable and, thus, the occupants cannot use them to evacuate the building. Details of this model are described in [12].

The stairs can become untenable either due to smoke spread or fire spread. In the case of smouldering or flaming non-flashover fires, the stairs can become untenable only by smoke spread. When the fire scenario is a flashover fire, then fire may also spread to the stairs making them untenable. If the stairs do not become untenable and the fire has burned out, then the occupants can safely escape from the building. If the stairs become untenable, then people cannot use them for evacuation and they become trapped in the building. The trapped occupants will then be subjected to the probabilities of smoke spread and fire spread.

The smoke spread probabilities represent a quantitative estimate of the risk to the occupants in the building as a result of smoke spread in the building. They are calculated at a reference time which is taken as the time of fire brigade arrival, if the fire brigade arrives. If the fire brigade does not arrive, then the reference time is taken to be the fire burnout time; except for the smouldering fires, in which case the reference time is taken to be 8 hours. This time was considered based on the assumption that if occupants are asleep, then they will probably be awaken after 8 hours and will then try to leave the building.

The smoke spread probability at any location in the building is assumed to be proportional to the Fractional Incapacitating Dose (FID) value as well as the temperature rise due to the fire at that location. The FID value is calculated from the $\mathrm{CO}$ and $\mathrm{CO}_{2}$ concentrations at that location [12].

Occupants who are still in the building at the reference time will be subjected to the toxic gases and temperature at their location at that time. For each fire, however, there exists the probability that the fire brigade will arrive, hence the smoke spread probabilities are calculated for each case independently and then combined to give the overall smoke spread probability using:

$$
\mathrm{P}[\mathrm{SS}]=\mathrm{P}[\mathrm{FBA}] * \mathrm{P}[\mathrm{SS}]_{\mathrm{tFBA}}+(1-\mathrm{P}[\mathrm{FBA}]) * \mathrm{P}[\mathrm{SS}]_{\text {burnout }}
$$

and for smouldering fires:

$$
\mathrm{P}[\mathrm{SS}]=\mathrm{P}[\mathrm{FBA}] * \mathrm{P}[\mathrm{SS}]_{\mathrm{tFBA}}+(1-\mathrm{P}[\mathrm{FBA}]) * \mathrm{P}[\mathrm{SS}]_{8 \text { hours }}
$$

The probability of fire brigade action and the time of fire brigade action have different values for each of the design fires and for occupants asleep and occupants awake, therefore, two sets of smoke spread probabilities for each design fire are calculated, one for occupants asleep and one for occupants awake. 


\section{RESULTS}

The risk-cost assessment model was used to carry out a series of runs to show the sensitivity of a number of input parameters on the Expected Risk to Life. These include, the fire resistance ratings (FRR) of the boundary elements, the reliabilities of the sprinkler system and the central alarm system, and the probability of the compartment of fire origin entrance door being open or closed. This type of sensitivity analysis is essential in demonstrating which of the input parameters, which are usually obtained from statistical data, need accurate evaluation.

For these tests, a timber-frame 3-storey apartment building was used. This building has four apartments per floor. The entrance doors of these apartments lead to an exterior corridor and exterior stairs. Four different models were considered: Model 1 has no central alarm system or sprinklers; Model 2 has a central alarm system (smoke detectors in each apartment are connected to a central alarm giving warning to the whole building) but no sprinklers; Model 3 has sprinklers but no central alarm system; and Model 4 has both sprinklers and a central alarm system. The nominal values used for all runs were 60 minutes for FRR, 0.93 for the reliability of the sprinkler system, 0.7 for the reliability of the central alarm system and 0.99 for the probability of the entrance door of the compartment of fire origin being closed. The results are shown in Figures 2 to 5, with the ERL values normalized by the ERL value of Model 1, which is used as the Reference Model.

Figure 2 shows the expected risk-to-life for the four models considered as a function of the fire resistance ratings. The results show the there is a large drop in the ERL when the FRR is increased from 30 minutes to 60 minutes for Models 1 and 2. The change in the ERL with FRR when sprinklers are installed (Models 3 and 4) is very small. Also very small improvements in the ERL values are seen when increasing the FRR values above 60 minutes. This can be attributed to the fact that a 60 minute FRR already prevents the fire from spreading quickly through the building and gives enough time for occupant evacuation.

\section{Relctive Expeded Riskto-Life Vs. Fire Resistance R ctings}

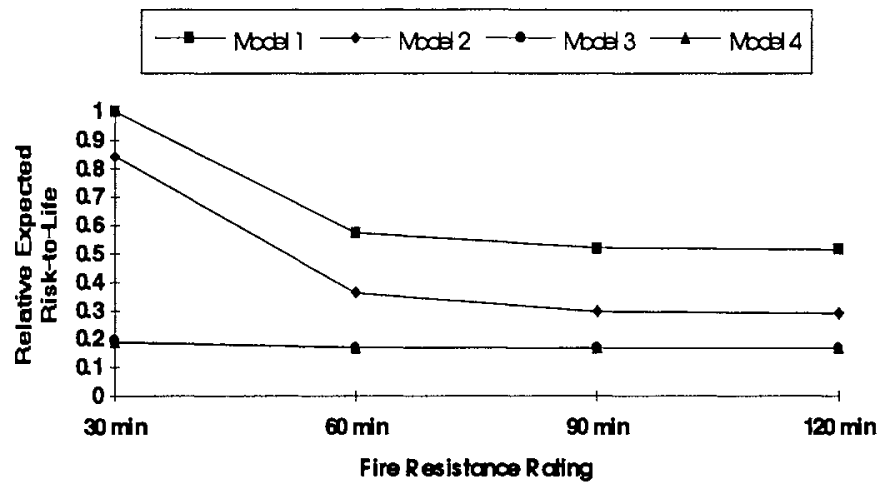

FIGURE 2. The effect of the FRR on the expected risk to life for the four models considered. 


\section{Relctive Expected Riskto- ife Vs. Probability of Door \\ Cosed}

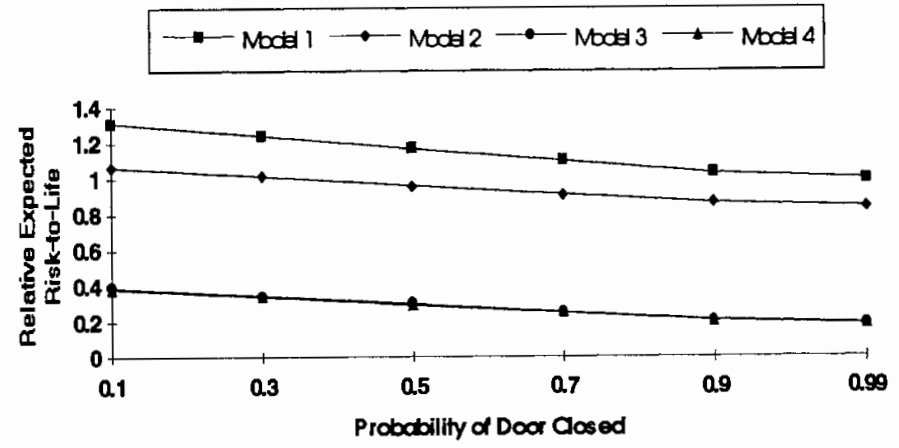

FIGURE 3. The effect of the probability of an apartment entrance door closed on the expected risk to life.

The probability of the apartment of fire entrance door being closed influences the results as it affects the probabilities of fire and smoke spread. Figure 3 shows that for all four models, the ERL value decreases as the probability of door being closed increases.

The effect of the reliability of the central alarm system on the expected risk to life is depicted in Figure 4. Increasing the reliability of the central warning system decreases the risk to life moderately for Model 2 , which has only a central alarm with no sprinklers. The impact of the reliability of the central alarm system when sprinklers are installed is not significant.

\section{Relative Expected Riskto-Life Vs. Relicbility of Centrd Alam}

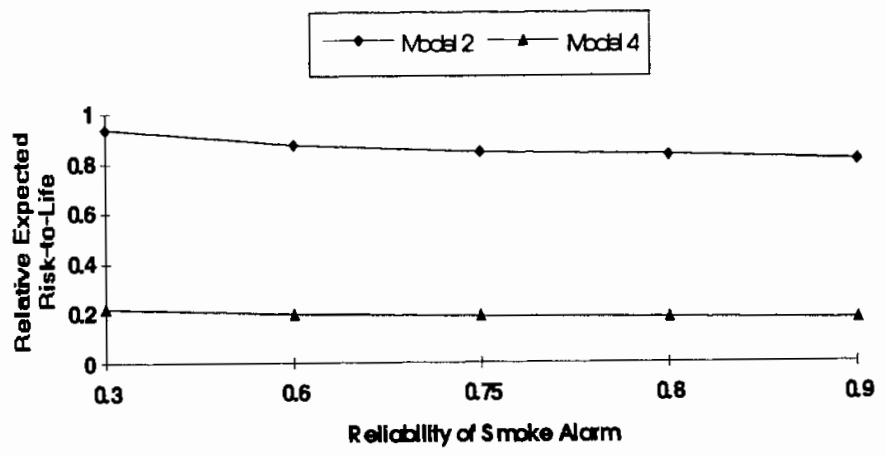

FIGURE 4. The effect of the reliability of a central alarm system on the expected risk to life. 


\section{Reldive Expected Riskto-Life Vs. Sprinkler Relictility}

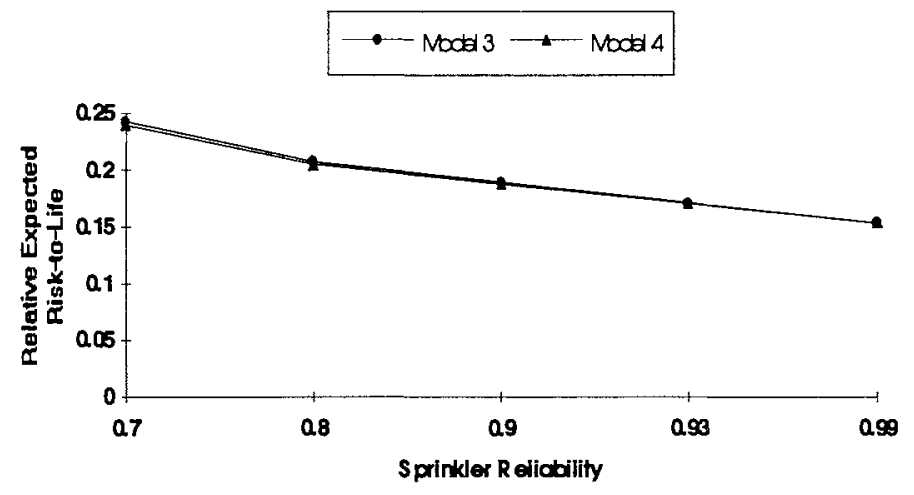

FIGURE 5. The effect of sprinkler reliability on the expected risk to life.

Figure 5 shows the effect of sprinkler system reliability on the expected risk-to-life. Only Models 3, and 4 are considered as these are the only models with sprinklers. The figure shows that, as the sprinkler system reliability increases, the ERL values decrease. The figure also shows that the ERL is 0.15 when the reliability is 0.99 . The reason the ERL value is not nearer zero is due to those fire scenarios that will not activate the sprinkler system. These scenarios are the smouldering fire scenarios and most of the flaming non-flashover fires which are assumed to be small enough not to activate sprinklers.

\section{SUMMARY}

This paper presented a computer model being developed at the National Fire Laboratory of the National Research Council of Canada for assessing the risks and the costs from fires in buildings. This model called the risk-cost assessment model, evaluates the risks and the costs through a systematic risk analysis process in which all possible fire scenarios are evaluated to determine their impact and then the results are combined using the probabilities of these scenarios to obtain the expected risk-to-life and the fire-cost expectation.

A sensitivity analysis was carried out of some of the input parameters using a three storey apartment building. The results show that, for this building, the fire resistance rating (FRR) has a great impact on the expected risk to life (ERL) when no sprinkler systems are installed, especially when the FRR is below 60 minutes. With sprinkler systems the ERL values are much lower than those of the models without sprinklers and are less affected by the level of FRR. In general, the results of this study show that, for this building, the presence of active fire protection systems is important, however, the variation of the reliability of these systems, within a reasonable range, is not that critical. 
ACKNOWLEDGMENT The authors would like to thank Mr. Charles Dutcher for his help in carrying out the computer runs.

\section{REFERENCES}

1. NFPA 550, "Guide to Fire Safety Concepts Trees", National Fire Protection Association, Quincy, 1986.

2. H. E. Nelson and A. J. Shibe, "A System for Fire Safety Evaluation of Health Care Facilities", NBSIR 78-1555, Center for Fire Research, National Bureau of Standards, Washington, 1980.

3. Friedman, R., "An International Survey of Computer Models for Fire and Smoke", J. of Fire Protection Engineering, Vol. 4, No. 3, 1992, pp.81-92.

4. Yung, D., G. V. Hadjisophocleous and Takeda, H., "Comparative Risk Assessments of 3-Storey Wood-Frame and Masonry Construction Apartment Buildings", Proceedings of Interflam '93, Oxford, England, March 30 - April 1, 1993, pp. 499-508.

5. Yung, D. and Beck, V. R., "A Risk-Cost Assessment Model for Evaluating Fire Risks and Protection Costs in Apartment Buildings", Proceedings of the International Symposium on Fire Engineering for Building Structures and Safety, Melbourne, Australia, Nov. 14-15, 1989, pp.15-19.

6. Beck, V. R. and Yung, D., "A Cost-Effective Risk-Assessment Model for Evaluating Fire Safety and Protection in Canadian Apartment Buildings", J. of Fire Protection Engineering, Vol.2, No.3, 1990, pp.65-74.

7. Hadjisophocleous, G. V. and Yung, D., "A Fire Risk and Protection Cost Assessment Model for Highrise Apartment Buildings", ASTM Fire Hazard and Fire Risk Assessment Symposium, San Antonio, Texas, 1990, ASTM-STP-1150, pp.224-233.

8. Mailvaganam, S., Yung, D. and Prencipe, M., "Ontario Fire Loss Statistics for the RiskCost Assessment Model", IRC Internal Report No. 622, National Research Council Canada, Ottawa, Canada, February 1992.

9. Gaskin, J. and Yung, D., "Canadian and U.S.A. Fire Statistics for Use in the Risk-Cost Assessment Model", IRC Internal Report No. 637, National Research Council Canada, Ottawa, Canada, January 1993.

10. Takeda, H. and Yung, D., "Simplified Fire Growth Models for Risk-Cost Assessment in Apartment Buildings", J. of Fire Protection Engineering, Vol.4, No.2, 1992, pp.53-66.

11. Fire Safety and Engineering, Warren Centre Report, The Warren Centre, The University of Sydney, Australia. 1989.

12. Hadjisophocleous, G. V. and Yung, D., "A Model for Calculating the Probabilities of Smoke Hazard from Fires in Multi-Storey Buildings", J. of Fire Protection Engineering, Vol.4, No.2, 1992, pp.67-80. 